\title{
Effects of Dog Ownership and Academic Success: A Correlational Study
}

\author{
Andrea Woehr ${ }^{1}$ \\ ${ }^{1}$ Lyman High School, Longwood, FL, USA \\ ABSTRACT
}

It is well known that dogs are effective stress relievers. Specifically, certified therapy dogs and service dogs have been proven to reduce stress in the academic realm. With the reduction of stress comes an increase in test scores and academic performance. Scientific trails have shown that dog visitations have helped children in elementary school increase their literacy and reading rates. College students report that meet and greets with therapy dogs during finals weeks have left them feeling more confident about upcoming exams. Though, what is not commonly considered are students at the high school level and the influence of dogs, particularly one that they own. This study involved the collecting and analyzing of surveys to see whether or not high schoolers who owned dogs had higher academic success as compared to their peers who didn't own dogs. The findings show that there is no such correlation between high schoolers who own dogs experiencing higher academic rates, however it did support the proven theory of dogs relieving stress.

\section{Introduction}

High schoolers' stress levels are on the rise. It is reported that teen stress levels during the school year are far beyond what is believed to be as healthy (Bethune, 2014, p. 20). With a ranking for stress in the school year at 5.8 on a 10point scale, teens predict this value will only continue to increase (Bethune, 2014, p. 20). This value trumps adults' reported stress levels, coming in at 5.1 on the 10-point scale (Bethune, 2014, p. 20). School is noted as being one of the most significant sources of stress for teenagers with academic competition and pressure being major contributors to stress in high school students today. Research has even found that "there is a negative relationship between students' perceived stress and academic performance" (Meyer and Larson, 2018, p. 453). High schoolers are not the only ones struggling with school-related stress. College students have also seen the influence of stress in an academic means. In fact, college students and high schoolers share similar tendencies and patterns when it comes to academic stress. Students in college "noted that exam-related stress contributes to negative academic outcomes for students; specifically, higher exam stress has been associated with poorer academic performance" (Barker, Barker, and Schubert, 2017, p. 278).

To limit the effect of stress on students, schools have begun introducing therapy dog visitation days or programs. The idea of this intervention lays in the fact that "human-animal interaction research supports the role of pets as a form of nonevaluative social support that may buffer the impact of a variety of stressful stimuli" (Barker, Barker, and Schubert, 2017, p. 279). The significance of the human-animal bond is not a new concept; evolving for around 15,000 years (Lenhard, 2018), it has proved its worth. As this relationship has developed over the years, it has taken on new roles. Connecting to the emergence of the human-canine bond, research has shown dogs to play a number of important roles in stress reduction. The Journal of College Counseling states that "several studies have documented stress reductions associated with interaction with dogs" (Barker, Barker, and Schubert, 2017, p. 278). Other studies have suggested that interactions with a therapy dog proved an effective treatment method, as it decreased stress and anxiety levels of college students (Adams, et al., 2017, p. 54). Due to research proving dogs to relieve human stress 
levels, specifically those of college students, it is believed that high schoolers who own dogs are more likely to display higher academic rates.

\section{Literature Review}

Recently, there has been an increase of research regarding therapy dogs and the benefits they provide. A therapy dog is certified in their training and has the classified role of providing comfort and emotional support without performing a given task. Due to increased awareness of such roles, therapy dogs have been at the forefront of science in the past years and have become widely accepted. West Chester University implemented a dog therapy program for their students in order to reduce their students' stress. Beginning with Tucker, a golden retriever, they quickly expanded their program to include Darla, a Bernese Mountain Dog, due to positive feedback and popularity of the program (Daltry and Mehr, 2015, p. 74-75). Tucker and Darla would visit the campus once a month and during the week of final exams. The counseling center at West Chester University saw an increased request for more visitation of the dogs throughout the school year and at a variety of events - suggesting that the implementation of the program was succeeding in helping students resonate with stress. In a random collection of feedback given by 54 students, $79 \%$ of participants said the therapy dogs brought exceptional value (Daltry and Mehr, 2015, p. 76). When asked about the stress reduction they experienced on a scale of one to five, one being no stress reduction and five being high reduction of stress, " $72 \%$ gave a rating of 5,21\% a rating of 4 , and $8 \%$ a rating of 3" (Daltry and Mehr, 2015, p. 76). Because no feedback of results came back with a rating lower than three, the introduction of therapy dogs in order to reduce stress did in fact work. Therefore, it is reasoned that high schoolers who own dogs should have higher academic performance, due to dogs providing comfort and a natural stress relief.

In regard to other benefits of therapy dogs, the University of Illinois conducted the Dynamic Indicators of Basic Early Literacy Skills Oral Reading Frequency (DIBELS ORF) exam on elementary students in the Sit Stay Read program, which allows second and third grade students to interact with therapy dogs in order to increase their reading fluency. Students were broken up into groups who either had association with dogs while reading and those that did not. The study consisted of the DIBELS ORF being given twice to each group, once as a base score and a second time at the end of the study. The test results showed that students who were exposed to the therapy dogs increased their average reading rate by 24 words per minute, as compared to an average of nine words per minute increase of students that did not have interaction with a therapy dog (Black, 2009, p. 36). The study also reported that since the introduction of the program "students do better on homework and their report card grades improve" (Black, 2009, p. 37). Even in a minimal to low stress environment, the therapy dogs in the Sit Stay Read program aided in the improvement of student's test scores, proving the academic benefits dogs hold. With the factor of stress eliminated in this study, it can be seen that the presence of dogs is increasing academic rates by a powerful and viable human-animal bond. In another study, researchers from The College of New Jersey and Lehigh University conducted a similar analysis based on a reading program in an elementary school in New Jersey that utilized therapy dogs for reading gains of their students. The students were tested with the Northwest Evaluation Association's (NWEA) Measures of Academic Progress (MAP) to evaluate their progress of reading fluency throughout the study (Kirnan, Ventresco, and Gardner, 2017, p.109). Students from kindergarten to fourth grade participated in this study, where once a week certified dogs would come and sit with the participants while they practiced their reading skills (Kirnan, Ventresco, and Gardner, 2017, p.109). The duration of this study was two years, which allowed for a series of data and feedback to be collected and the long-term benefits of dog-assisted literacy programs (DLPs) to be analyzed. In a statistical analysis, results proved that DLPs showed "a positive impact on reading scores in lower grades" (Kirnan, Ventresco, and Gardner, 2017, p.112). The results also showed that kindergarteners and first graders who were in the test group 'outperformed' the control group of their grade level (Kirnan, Ventresco, and Gardner, 2017, p.112). Reading gains as early as kindergarten, when children are just starting to read, are extremely influential for the rest of an academic career. As early as the age of four, therapy dogs are providing benefits to children and their academic success. Because the duration of this study was for an extended time, the results suggest that the gain in academic performance of students who 
interacted with dogs is not just immediate, but prolonged. Due to ownership of a dog being an expanse of time, students who own dogs should most likely have higher academic rates than those who don't have this exposure. With the recent increase in knowledge and research of benefits therapy dogs provide to students, there has been a gap of research regarding domestic dogs and the benefits they too can provide. Domestic dogs are considered as those that are pets with no specific training certifications. In her study, Emily Gerace, who is associated with the College at Brockport, evaluates the correlation of college students who own domestic dogs having higher academic productivity rates. Gerace's participants were college students of surrounding universities near the College at Brockport. Participants were selected from their ownership status of a domestic dog and a scale rating on the Pet Attitude Scale, needing at least a score in the 50th percentile to be included; they were then grouped into two groups, those who owned $\operatorname{dog}(\mathrm{s})$ and those who didn't (Gerace, 2017, p. 9). An initial questionnaire was collected at the beginning of the study, along with their score of the Pet Attitude Scale, determining their disposition towards animals (Gerace, 2017, p. 9). The same surveys were sent out once a month, throughout the course of the semester, with a slight alteration of questions to the dog owning group. Gerace used a specific statistical analysis program to analyze the response differences and compare them between the two groups. The results showed that there was an association between college students who owned a domestic dog experiencing greater levels of productivity. Gerace also credited that "overall academic performance, perceived stress, and involvement are higher when owning a domestic dog versus not owning a dog" (2017, p. 11). Dog associated benefits don't just stop with certified therapy animals but rather can be stimulated from pet dogs as well. Such benefits are proving that no matter therapeutic or domestic, dogs have the capability of improving various factors regarding education when it comes to students - an important aspect in relativity for the research that is to be conducted.

Interactions with dogs have shown significant benefits of mental, emotional, and physical health pertaining to college and elementary students. However, very little research has been conducted with high schoolers regarding their responses and improvements, academically, to therapy dogs or domestic dogs. Regardless of their certifications or qualifications, dogs have shown the correlation of relieving stress and increasing academic performance; with this in mind, the need to solidify the relationship between high schoolers' dog ownership and academic performance is critical in the science community in the knowledge it can offer.

\section{Methods}

\section{Objective}

Through focusing on ownership of domestic dogs, the natural bond between high schoolers and their dogs could be evaluated. The purpose of this study was to see whether or not high schoolers who own dogs experience greater academic success as compared to high schoolers who don't own dogs. Through this evaluation, the study's intent was to merely suggest whether a relationship was present.

\section{Study Design}

A correlational approach was used for the purposes of this study. The two factors, dog ownership and academic performance, were measured and assessed in relation to one another through the collection of survey responses. In the interest of students' time a survey was chosen as the instrument. It was approximated that the completion of the survey would take 15 minutes, however, participants were informed that they could stop at any time and that all recorded answers were anonymous. Through the use of a survey, specific results were collected and both quantitative and qualitative responses were gathered in this approach. 


\section{Survey Components and Distribution}

After review and approval from the international review board (IRB) surveys with attached informed consent (See Appendix A) were distributed electronically to high school students, between grades 9th and 12th. Students were asked at random, and from a variety of high schools, if they were eligible and willing to participate. A parental consent (See Appendix B) was given to students under the age of 18 and collected before those students were allowed to participate; this was done in order to ensure their participation. Those who were 18 or older were able to begin the survey without the need of parent approval.

The survey was split into two sections: academic-related questions and dog-related questions. The academicrelated questions asked students their grade level, grade point average (GPA), and the types of classes they take. Following the Florida Department of Education's grading scale, the GPA collected in this study was weighted off of a 4.0 scale. In responding to classes, students were given the options of advanced placement (AP), international baccalaureate (IB), dual enrollment (DE), honors, and standard and were asked to select all that apply to them. Through understanding the types of classes students take, the course load and rigor of each student can be evaluated. This information is critical to the study in showing how much time students invest towards their academics compared to the time that is relatively invested to those who own dogs. The participants were then asked if they owned a dog. Those who answered 'no' submitted their survey responses and were put into the non-dog owning category. Those who responded 'yes' to owning a dog moved on to the dog-related survey questions.

In the dog-related survey questions, students were asked a series of questions that reflected the ownership of their $\operatorname{dog}(\mathrm{s})$. The questions were intended to show the level of attachment and devotion the student has to their $\operatorname{dog}(\mathrm{s})$; stemming from Gerace's longitudinal research that "overall academic performance, perceived stress, and involvement are higher when owning a domestic dog versus not owning a dog" (11). The beginning questions in this section covered the basis of how many dogs the student owns; how long they've owned their $\operatorname{dog}(\mathrm{s})$; and how much time they spend with their $\operatorname{dog}(\mathrm{s})$. As the survey continued, questions would progress into those that would provide a qualitative answer. Such questions included if the student felt a reduction of stress after spending time with their $\operatorname{dog}(\mathrm{s})$ and whether or not they felt emotionally connected to them. Answer choices to these questions were in the form of a scale. The scale ranged as follows: strongly disagree, disagree, neither agree or disagree, agree, and strongly agree. The use of this scale provided participants with the flexibility to answer accordingly to their personal feelings or in a neutral way, as compared to a limited and closed 'yes/no' type of answer. Similar to the academic-related questions, the dog-related questions were formulated so that they reflected clear, definitive questions that would lend to a more solid analysis. Essentially, showing that misleading questions were not included in this survey in order to protect the ethicality of the study and obtain honest, accurate answers from the participants. Once the students who were carried into the dogrelated questions finished and submitted their survey, they were placed into the dog owning category.

Responses recorded in the academic-related section of the survey were analyzed through a statistical analysis and calculation of the correlation coefficient, sample mean, and sample standard deviation, regarding the factors of GPA and dog ownership. Responses in the dog-related section of the survey were analyzed through a point system (See Appendix C) through the belief that in "establishing item weights through principal component analysis in order to obtain a set of maximally reliable scale scores" (Hofstee, Hendricks, and Ten Berge 908). Scoring responses through a point system was selected as the data analysis in this section so that the depth of the bond between the participant and their $\operatorname{dog}(\mathrm{s})$ could be measured. In doing so, qualitative answers could be quantified, allowing for further calculation and interpretation of the survey responses. Different responses were awarded a different number of points. For example, if they had more responsibilities when it came to taking care of their dog, they were given a higher number of points than students who only had, say one responsibility. This same idea fell for students who had owned their dogs for a longer time period; these students were given more points than those who had shorter durations of ownership. Points were awarded in this way to show how long the human-animal relationship, one that Emily Lenhard describes in The Human-Animal Bond throughout Time, had existed. In doing so, a proper weight to how deep the relationship between the student and their dog could be established, leading to the analysis and conclusion of results. 


\section{Results}

\section{Survey}

The survey yielded 47 responses; 16 of which were associated with non-dog owning responses and 31 that included dog owning responses. Figure 1 shows the percentage of participants in each grade level, with the majority of responses coming from 12 th grade students.

\section{What grade are you in?}

47 responses

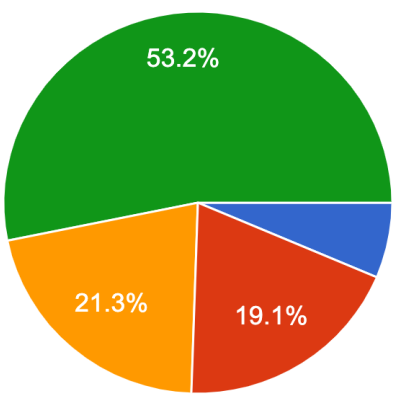

Figure 1. Grade level of participants.

Out of all of the responses only six students took standard level classes. Honors and AP classes were selected with nearly the same count, with AP classes having two more selections for a total of 39 as compared to honors' 37 - showing that this survey consisted of the majority of students to have an average to extremely advanced course rigor; which is reflected off the sample mean GPA, $\underline{x}=4.037$. The standard deviation of the sample solved to be 2.007, showing a close and similar response trend regarding GPAs. With the sample mean being nearly equal to the $4.0 \mathrm{GPA}$ scale, the majority of participants in this survey had GPAs higher than 4.0.

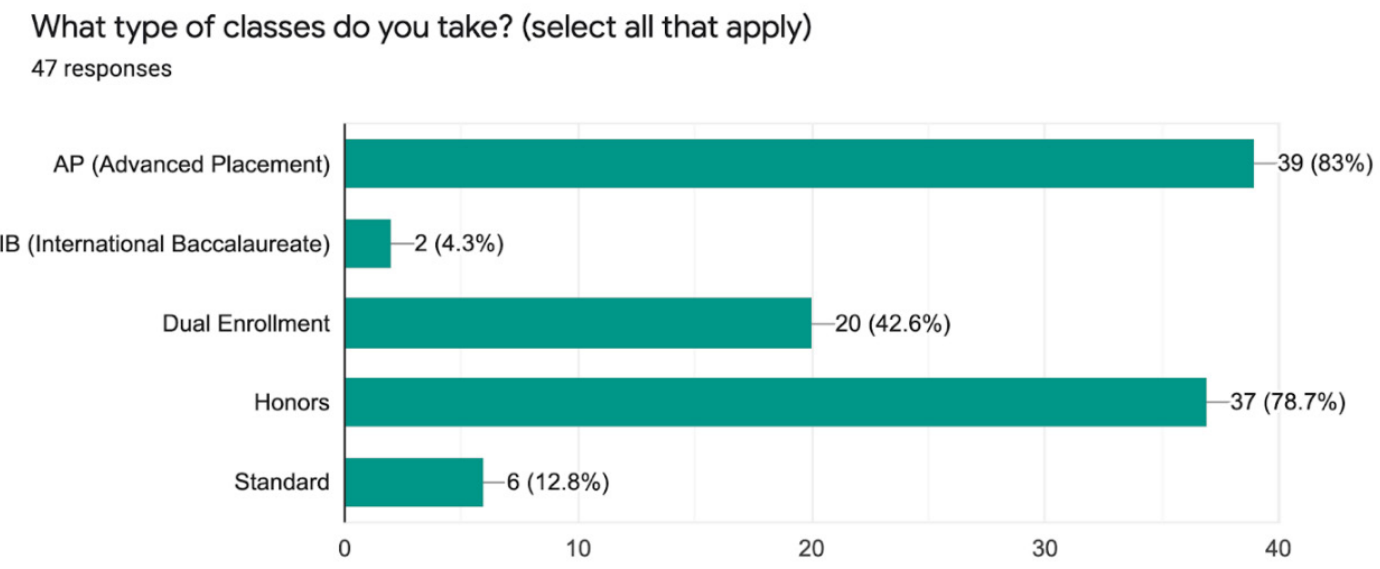

Figure 2. Participation of participants in different levels of classes. 
GPA associated with each participant's response for owning a dog can be seen in Table 1. The responses for dog ownership were converted to numerical values, 'yes' being +1 and 'no' being -1 , in order for a correlation coefficient to be established. Calculations showed the correlation coefficient to be $r=-0.0599$, proving relatively no relationship between high school students who own a dog to have a higher academic success, as compared to their peers that don't own a dog.

Table 1. GPA with prevalence of dog ownership amongst participants.

\begin{tabular}{|c|c|}
\hline GPA & Dog Ownership \\
\hline 3.3 & -1 \\
\hline 3.3 & -1 \\
\hline 4.256 & -1 \\
\hline 4 & 1 \\
\hline 4.2 & -1 \\
\hline 4.39 & 1 \\
\hline 4.6 & -1 \\
\hline 3.5 & 1 \\
\hline 4.1 & -1 \\
\hline 4.325 & -1 \\
\hline 4.565 & 1 \\
\hline 4.655 & 1 \\
\hline 4.018 & 1 \\
\hline 4.68 & -1 \\
\hline 3.93 & 1 \\
\hline 4.429 & -1 \\
\hline 4.63 & 1 \\
\hline 3.75 & 1 \\
\hline 3.098 & 1 \\
\hline 4.4 & -1 \\
\hline 3.6 & 1 \\
\hline 4.13 & 1 \\
\hline 3.9 & 1 \\
\hline 4 & 1 \\
\hline 4.36 & 1 \\
\hline
\end{tabular}

\begin{tabular}{|c|c|}
\hline GPA & Dog Ownership \\
\hline 3.8 & -1 \\
\hline 4.2 & 1 \\
\hline 4.3 & 1 \\
\hline 4.8 & 1 \\
\hline 3.45 & 1 \\
\hline 3.45 & 1 \\
\hline 4 & 1 \\
\hline 4.061 & 1 \\
\hline 4.024 & 1 \\
\hline 4.2 & 1 \\
\hline 3.76 & 1 \\
\hline 3.9 & 1 \\
\hline 3.7 & 1 \\
\hline 4 & 1 \\
\hline 4.1 & 1 \\
\hline 4.1 & 1 \\
\hline 3.8 & 1 \\
\hline 4.1 & -1 \\
\hline 4.429 & -1 \\
\hline 2.9 & -1 \\
\hline 4 & -1 \\
\hline 4 & -1 \\
\hline
\end{tabular}

In the dog ownership portion of the survey, a clear majority of students owned one dog with a full breakdown shown in Figure 3. The duration of ownership saw similar response percentages for categories ' $3-4$ years' and ' 11 or more years' (Figure 3.2). And ranking above other responses, students reported that they spend 5 or more hours with their dog on a weekly basis. 
How many dogs do you own/have?

31 responses

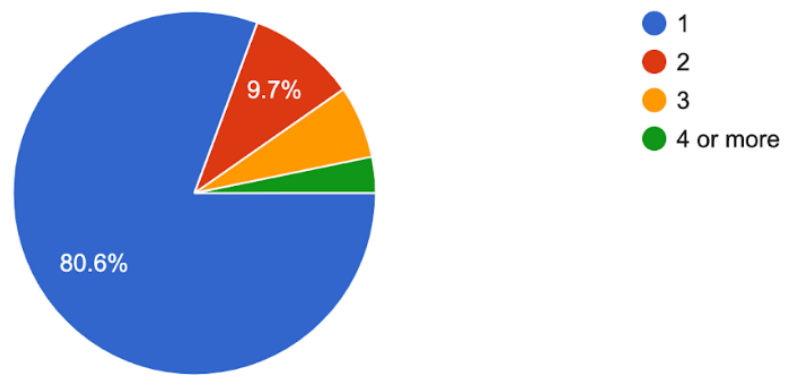

Figure 3. Average number of dogs owned by participants.

Approximately how many years have you owned/had your dog(s)?

31 responses

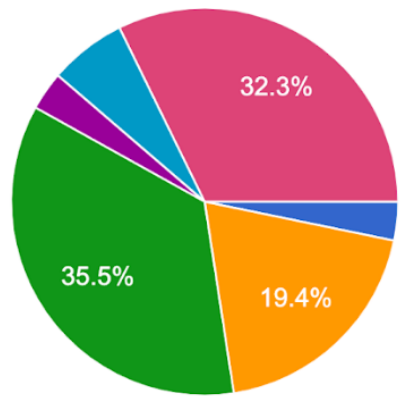

Less than a year

1 - 2 years

3 - 4 years

$5-6$ years

7 - 8 years

9 - 10 years

11 or more years

Figure 4. Average number of years of ownership.

Approximately how much time do you spend with your dog(s) on a weekly basis? 31 responses
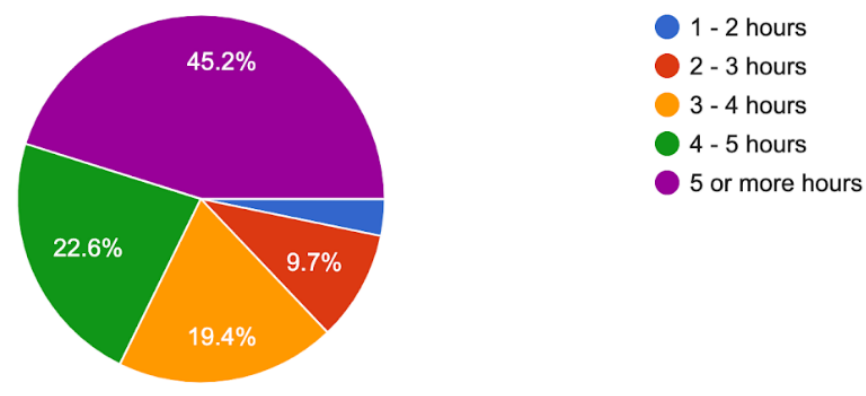

Figure 5. Average amount of time spent with the $\operatorname{dog}(\mathrm{s})$. 
For participants who owned dogs, a correlation coefficient of $r=.130$ was calculated for the relationship of GPA to the depth of bond in students. The average GPA of students who owned dogs was 4.019. Compared to the GPA of students who didn't own dogs, 4.070, the GPA of students owning dogs ranked lower by .051, supporting the dismissal of high schoolers who own dogs have higher academic performance. The GPA paired with the number of points awarded to the relationship in dog owning responses can be found in Table 2 (See Appendix C p. 26 for point system). The average points in depth of relationship awarded, 19.181, shows a deep sense of relationship between participants and their $\operatorname{dog}(\mathrm{s})$ in this study as the highest number of points awarded could be 17.5.

Table 2. GPA with the associated depth of relationship scores.

\begin{tabular}{|c|c|}
\hline GPA & Depth of Relationship \\
\hline 4 & 11 \\
\hline 4.39 & 19.89 \\
\hline 3.5 & 24 \\
\hline 4.565 & 22.065 \\
\hline 4.655 & 20.155 \\
\hline 4.018 & 23.518 \\
\hline 3.93 & 18.43 \\
\hline 4.63 & 25.63 \\
\hline 3.75 & 16.25 \\
\hline 3.098 & 23.098 \\
\hline 3.6 & 10.1 \\
\hline 4.13 & 22.13 \\
\hline 3.9 & 23.4 \\
\hline 4 & 17.5 \\
\hline 4.36 & 19.86 \\
\hline 4.2 & 19.2 \\
\hline 4.3 & 18.3 \\
\hline 4.48 & 20.48 \\
\hline 3.45 & 19.95 \\
\hline 4 & 25 \\
\hline 4.061 & 14.061 \\
\hline 4.024 & 19.524 \\
\hline 4.2 & 23.7 \\
\hline 3.76 & 23.26 \\
\hline 3.9 & 15.9 \\
\hline 3.7 & 20.7 \\
\hline 4 & 20.5 \\
\hline 4.1 & 16.6 \\
\hline 4.1 & 16.1 \\
\hline 3.8 & 11.8 \\
\hline 4 & 12.5 \\
\hline
\end{tabular}




\section{Discussion}

Based on the negative, nearly zero, correlation coefficient that was calculated, there is no present relationship that high schoolers who own dogs have higher academic performance. Even with it being hypothesized that there would be a positive correlation, it would be understandable to have had a negative correlation. With prior research suggesting that dogs relieve stress, it was hypothesized that students who owned dogs would have less stress and therefore would have higher academic performance rates. Though, reasoning for a negative relationship could be suggested because ownership of a dog takes up time and responsibility, possibly suggesting that this could distract high school students in allowing them to succeed in academics. With no correlation presented among these two factors, as one variable were to increase, the other would not be affected. This can be coherent because if GPA, which was being used to measure academic performance, increased this would not necessarily suggest the number of high schoolers who own dogs would also rise. However, comparing the mean GPA's of the non-owning and dog owning groups showed that on average high schoolers who owned dogs, had a slightly lower GPA, most likely because of the responsibilities that were shared with owning a dog. More than half of students in the dog owning category reported having three or more responsibilities to their dog, such as feeding, training, exercising, and grooming. In the amount of time that these responsibilities are to take out of a student's day, potential study time is depleted. To translate this weekly, Figure 3.3 showed that most students spent five or more hours with their dog in a given week. On top of this $45.2 \%$, another $22.6 \%$ spent four to five hours with their $\operatorname{dog}(\mathrm{s})$ on a weekly basis. With the majority of students selecting extended time frames, an impact on student's time shows that students who own dogs have a decreased amount of time to study and focus on academics, reasoning for the lower overall GPA of the dog owning group.

Despite the absent relationship between high schoolers owning dogs affecting their academic performance, $67.7 \%$ of students who owned dogs agreed or strongly agreed that after spending time with their dog(s) they felt less stressed. In this, the results support what other research has proven by Sandra Barker, Randolph Barker, and Christine Schubert, as well as Rachel Daltry and Kristin Mehr, that dogs are effective stress relievers. In the survey responses, $90.3 \%$ of dog owning students felt an emotional connection to their $\operatorname{dog}(\mathrm{s})$. This emotional connection could be reasoned to be the human-animal bond established by Lenhard and her research. Though no new relationships between dogs and academic factors were formed during this study, the study did allow for prior research to be further supported.

\section{Implications}

The largest limitation in this study was the amount of survey responses received. Though the responses met the required 30 so that proper analysis and statistical significance could occur, more responses could have yielded a different outcome or created a larger variety. Through a larger collection of responses, there could have been a wider range of GPAs. Though, having a high GPA is an accredited factor among students, this study was limited in the number of lower GPAs which most likely affected the analysis of results. The reason for this being that there was a greater number of responses that represented more advanced level classes, as compared to a smaller representation in lower ranked classes. Another limitation in this sample is that it contained a majority of upperclassmen. In a ratio of 35 to 12 , juniors and seniors compared to sophomores and freshmen made up more than half of the survey responses. The causation of this is most likely from a parental consent form needed to be signed before minors could participate. Though, the distribution of surveys made sense to the researcher, for future research there are other recommended ways. By sending the parental consent separate from the survey, factors of time and feasibility were stretched. Instead, it would have been more efficient to incorporate the parental consent into the survey itself. This would have made gathering survey participants easier and created more diversity among grade levels. Minors could have completed the survey in the proximity of their parents for their signature, as compared to having to get the parental consent form signed, returning it, and then being allowed to take the survey; thus, solving both limitations addressed. Human error 
by both the participants and the researcher, as well as outside influences not associated with this study can be deemed a limitation too.

\section{Limitations}

One thing that can be developed upon through the information that was found in this research and prior research, is the continued use of dogs to relieve academic-related stress, specifically in high schools. It is stated by the Americans with Disability Act National Network that "emotional support animals, therapy animals, and companion animals are seldom allowed to accompany students in public schools" (7). Though there has been increased awareness of their benefits and inclusion of their roles, the exception to this comes in their lack of presence among high school campuses. As seen in the literature review, a number of college campuses and elementary schools are implementing therapy dog programs, though it is rarely heard of for a therapy dog to be present on a high school campus. Some Sheriff's Offices, Seminole County being one, have taken initiative in bringing in comfort dogs to their district's schools. Through increased education to school districts on how therapy dogs could limit the stress of students and improve their mental health, there could be a greater chance for high school students to see their own district's comfort dog on their school campus. Before this could take place, however, further guidelines would need to be set in place, with proper training and handling on both the dogs and handlers' part being included.

\section{Future Research}

Future research should be done in order to fully conclude that high schoolers who own dogs do not, in fact, affect their academic performance. Even though a slight negative correlation coefficient was found in this study, a larger and more inclusive sample should be surveyed. It is apparent and widely felt that high schoolers are less stressed when they spend time with their dogs. With the tremendous amount of pressure they're under, it's important that students who don't have access to this opportunity have the ability to embrace the emotional connection and natural cortisol release. If high schools were to integrate a form of therapy dog program into their school, they may not see a change in academic performance, but they're guaranteed to have a healthier and happier student body, which is critical for this day and age.

\section{References}

Adams, et al. (2017). The Mental Health Benefits of Having Dogs on College Campuses. Modern Psychological Studies, 22(2), 50-59.

Barker, S., Barker, R, \& Schubert, C. (2017). Therapy Dogs on Campus: A Counseling Outreach Activity for College Students Preparing for Final Exams. Journal of College Counseling, 20(3), 278-288. doi.org/10.1002/jocc. 12075

Beckstead, B. (2019). Massena Central School District crafts policy regarding therapy dogs in schools. NNY360.

Bethune, S. (2014). Teen stress rivals that of adults. American Psychological Association, 45(4), 20.

Black, S. (2009). Sit, Stay, and Read. American School Board Journal, 196(12), 36-37.

Brennan, J, \& Nguyen, V. (2014) Service Animals and Emotional Support Animals. ADA National Network, 7.

Daltry, R., \& Mehr, K. (2015). Therapy Dogs on Campus: Recommendations for Counseling Center Outreach. Journal of College Student Psychotherapy, 29(1), 72-78. doi.org/10.1080/87568225.2015.976100 
Feighan, M. (2020). Going to the dogs: More courts, schools use therapy dogs to lower anxiety, stress. The Detroit News.

Gerace, E. (2017). The association between owning domestic dogs as pets and the productivity amongst college students. The College at Brockport: State University of New York.

Hofstee, W., Hendriks, J., \& Ten Berge, J. (1998). How to score questionnaires. Personality and Individual Differences. 897-909. doi: 10.1016/S0191-8869(98)00086-5.

Kirnan, J., Ventresco, N. E., \& Gardner, T. (2018). The Impact of a Therapy Dog Program on Children's Reading: Follow-up and Extension to ELL Students. Early Childhood Education Journal, 46(1), 103-116. doi.org/10.1007/s10643-017-0844-z

Lenhard, Emily. (2018). The Human-Animal Bond throughout Time. Michigan State University: College of Veterinary Medicine.

Meyer, S., \& Larson, M. (2018). Physical Activity, Stress, and Academic Performance in College: Does Exposure to Stress Reduction Information Make a Difference? College Student Journal, 52(4), 452-457.

(2014-2015). DOE Information Database Requirements. Florida Department of Education, 1, 1-2. 